\title{
Fu-Zheng-Jie-Du Ointment Enhances the
}

Therapeutic Efficacy of 5-fluoropyrimidine by Inhibiting TIE2-expressing Monocyte/macrophagemediated Angiogenesis in a Mouse Gastric Cancer Model

\section{Zhe Wu}

China Academy of Chinese Medical Sciences

\section{Ruike Gao}

China Academy of Chinese Medical Sciences

\section{Manman Xu}

China Academy of Chinese Medical Sciences

\section{Zhuo Song}

China Academy of Chinese Medical Sciences

Qihang Tian

Shaanxi University of Chinese Medicine

Jie Lj ( $\sim$ drjieli2007@126.com )

Department of Oncology, Guang'anmen Hospital, China Academy of Chinese Medical Sciences, Beijing, 10053, China https://orcid.org/0000-0002-3461-8816

\section{Research}

Keywords: gastric cancer, Fu-Zheng-Jie-Du ointment, TIE2-expressing monocytes/macrophages, angiogenesis, chemotherapy

Posted Date: September 17th, 2020

DOI: https://doi.org/10.21203/rs.3.rs-76165/v1

License: (c) (i) This work is licensed under a Creative Commons Attribution 4.0 International License. Read Full License 


\section{Abstract}

Background: Most cases of gastric cancer (GC), which is one of the most common cancers in China, are diagnosed at an advanced stage. The first-line treatments for GC include 5-fluoropyrimidine (5-FU)-based chemotherapy. However, the cancer cells may develop 5-FU resistance. The inhibition of angiogenesis can be an alternative therapeutic strategy for GC. Recent studies have demonstrated that TIE2-expressing monocytes/macrophages (TEMs), a subtype of tumor-associated macrophages (TAMs), exhibit profound pro-angiogenic activity. The herbs used in traditional Chinese medicine can be a potential source of anticancer agents and can improve the therapeutic efficacy of chemotherapy drugs. In this study, the role of TEMs in the synergistic anti-cancer effects of Fu-Zheng-Jie-Du ointment (FZJD) and 5-FU was evaluated.

Methods: The migration of TEMs was evaluated using the transwell assay. Tube formation assay and quantitative real-time polymerase chain reaction analysis were used to determine the pro-angiogenic activity of TEMs. Tumor-bearing mouse model and immunohistofluorescence stain were used to evaluate the anti-tumor effect of FZJD and the underlying mechanism.

Results: FZJD inhibited the migration and pro-angiogenic activity of TEMs. Additionally, tumor growth in the mice co-treated with FZJD and 5-FU was lower than that in the mice treated with FZJD or 5-FU. Immunohistofluorescence stain revealed that the migration of TEMs was not inhibited upon treatment with FZJD alone or in combination with 5-FU. Moreover, treatment with FZJD did not decrease the endothelial cell population. In contrast, the treatment combination of FZJD and 5-FU markedly decreased the endothelial cell population.

Conclusions: FZJD improves the anti-cancer efficacy of 5-FU through the inhibition of TEM-mediated angiogenesis.

\section{Background}

In China, gastric cancer (GC) is the third most common cancer and accounts for $13.6 \%$ of cancer-related death in 2018 [1]. Most GC cases are diagnosed at an advanced stage, which has limited therapeutic interventions. Hence, patients with GC exhibit a poor five-year survival rate [2]. Chemotherapy is the corner stone for the systemic treatment of cancer. The first-line treatments for GC include 5-fluoropyrimidine (5FU)-based chemotherapy [3]. However, the development of 5-FU resistance in the cancer cells is the major limiting factor for improving the overall survival (OS) of patients with GC.

Anti-angiogenesis therapy represents an important strategy for GC. Various studies have demonstrated that the tumor-associated macrophages (TAMs) play essential role in tumor angiogenesis [4]. De Palma et al. reported that TIE-2-expressing monocytes/macrophages (TEMs), which are a subtype of TAMs, exhibited profound pro-angiogenic activity [5]. The selective depletion of TEMs markedly inhibited angiogenesis in the mouse tumor model. Additionally, the vascularization in mice co-injected with TEMs and tumor cells was higher than that in mice co-injected with TIE-2- ${ }^{-}$TAMs and tumor cells. TEMs have been detected in various solid tumors [6-8]. In patients with GC, the proportion of TEMs in the tumor 
increases with tumor grade and the increased proportion of TEMs is correlated with enhanced cancer recurrence rate and poor prognosis [9]. This indicated that TEMs are a promising therapeutic target for GC.

Angiopoietins (ANGs) are the specific ligands that bind and activate TIE-2 [10]. ANG-2, which is upregulated in various tumor types, recruits TEMs from the circulation to the tumor mass [11-13]. Pretreatment with ANG-2 upregulates the expression of vascular-promoting genes, such as VEGFA, MMP9, and COX2 in the TEMs [14].

In China, Fu-Zheng-Jie-Du ointment (FZJD) is orally administered to treat GC. Previous study demonstrated that FZJD exert anti-tumor effect by re-polarizing M2 type TAMs to M1 [15]. This study aimed to evaluate the role of TEMs in the synergistic anti-cancer effects of FZJD and 5-FU. The findings of this study indicated that FZJD inhibited tumor growth and improved the anti-cancer efficacy of 5-FU by inhibiting TEMs-mediated angiogenesis.

\section{Methods}

\section{Preparation and phytochemical analysis of FZJD}

FZJD comprises the following eight herbal plants: Hedysarum multijugum Maxim. (Huang-Qi), Fallopia multiflora (Thunberg) Harald (He-Shou-Wu), Bistortae Rhizoma (Cao-He-Che), Actinidia arguta (Siebold \& Zucc.) Planch. ex Miq. B (Teng-Li-Gen), Smilacis Glabrae Rhizoma (Tu-Fu-Ling), Codonopsis Radix (DangShen), Fructus Lycii (Gou-Qi), and Atractylodes macrocephala Koidz (Bai-Zhu) in the ratio 2:1:1:1:1:1:1:1. FZJD ointment was provided by the Pharmaceutical Preparation Center of Guang'anmen Hospital, China Academy of Chinese Medical Sciences. Bai-Zhu was soaked in water for $24 \mathrm{~h}$. Next, the mixture was subjected to steam distillation in another container and obtained $450 \mathrm{~mL}$ distillate. The residue was boiled with water for $1 \mathrm{~h}$ and the decoction was mixed with $450 \mathrm{~mL}$ of distillate. The other herbs were decocted twice with water for $1 \mathrm{~h}$ each. The decoction from the two steps was mixed and filtered. The filtrates obtained from Bai-Zhu and other herbs were mixed and the mixture was concentrated through evaporation under reduced pressure to obtain the final ointment (relative density of $1.20-1.25 \mathrm{~g} / \mathrm{cm}^{3}$ at 50 $\left.{ }^{\circ} \mathrm{C}\right)$. The chemical constituents of FZJD ointment were analyzed using high-performance liquid chromatography (HPLC). The test solution was prepared by dissolving FZJD ointment in methanol. HPLC analysis was performed in an Agilent 1200 HPLC (DAD) system equipped with a C18 analytical column $(250 \times 4.6 \mathrm{~mm}, 5 \mu \mathrm{m})$. The mobile phase for gradient elution comprised acetonitrile and water. The following standards were used for quality control: calycosin-7-glucoside and astragaloside IV $(H$. multijugum Maxim); rhein, emodin, physcion, and 2,3,5,4' tetrahydroxystilbene 2-0- $\beta$-D glucoside ( $F$. multiflora); gallic acid (Bistortae Rhizoma); epicatechin (A. arguta); astilbin (Smilacis Glabrae Rhizoma); lobetyolin (Codonopsis Radix); betaine (Fructus Lycii); atractylenolide I, II, and III (Atractylodes macrocephala); fructose, glucose, and sucrose (saccharides). All standards were purchased from the National Institutes for Food and Drug Control (Beijing, China). 


\section{Animals}

Male 615 mice (aged 4-6 weeks; weighing 18-20 g) and male Sprague-Dawley (SD) rats (aged 4-6 weeks; weighing 190-200 g) were purchased from the Vital River Company (Beijing, China). All animals were housed in a temperature and humidity-controlled facility. The animals had free access to food and water. All animal experiments were performed according to the Guidelines for the Care and Use of Laboratory Animals, Ministry of Science and Technology, China. This study was approved by the Ethical Committee of Guang'anmen Hospital, China Academy of Chinese Medical Sciences, Beijing (IACUCGAMH-2020-006).

\section{Cell culture}

The murine GC cell lines, mouse forestomach carcinoma cell (MFC) and mouse aorta endothelial cell (MAEC) were purchased from the Institute of Basic Medical Science Chinese Academy of Medical Science (Beijing, China). MFCs and MAECs were cultured in Dulbecco's modified Eagle medium (DMEM) medium supplemented with $10 \%$ fetal bovine serum, $100 \mathrm{U} / \mathrm{mL}$ penicillin, and $100 \mathrm{~g} / \mathrm{mL}$ streptomycin (all from Thermo Fisher Scientific, Waltham, MA, USA). All cells were maintained at $37^{\circ} \mathrm{C}$ and $5 \% \mathrm{CO}_{2}$ in a humidified chamber.

\section{Establishment of a tumor-bearing mouse model and drug administration}

The mice were allowed to acclimatize for one week. The MFCs $\left(2 \times 10^{5}\right.$ in $\left.0.2 \mathrm{~mL}\right)$ were injected into the right axilla of 615 mice. The animals randomly divided into the following four groups ( $n=10 /$ group) were treated with the test agents the next day: Control group, administered with phosphate-buffered saline (PBS) by oral gavage (OG; $0.2 \mathrm{~mL} /$ day) and intraperitoneally injected with PBS ( $0.1 \mathrm{~mL}$ for thrice a week); 5 -FU group, administered with PBS by OG $(0.2 \mathrm{~mL} /$ day) and intraperitoneally injected with 5-FU (20 $\mathrm{mg} / \mathrm{kg}$ bodyweight, thrice a week); FZJD group, administered with FZJD $(0.625 \mathrm{~g} / \mathrm{mL})$ by OG $(0.2$ $\mathrm{mL} /$ day $)$ and intraperitoneally injected with PBS (0.1 mL; thrice a week); FZJD+5-FU, administered with both FZJD and 5-FU following the treatment protocols of FZJD and 5-FU groups. The treatment period for all groups was two weeks. The mice were sacrificed by cervical dislocation on the day after the final drug administration. The tumor tissues were excised and weighed.

\section{Preparation of FZJD-containing serum}

The SD rats were randomly divided into the following two groups: blank serum group, administered with saline; FZJD serum group, administered with FZJD $(0.4375 \mathrm{~g} / \mathrm{mL})$ by $O G(2 \mathrm{~mL}$; twice a day for five consecutive days). The animals had free access to food and water until $12 \mathrm{~h}$ before blood collection. All rats were anesthetized by intraperitoneal injection of $1 \%$ pentobarbital sodium. The blood samples collected from the abdominal aorta at $1 \mathrm{~h}$ post-final OG administration under sterile conditions were incubated at room temperature for $4 \mathrm{~h}$ and centrifuged at $3000 \mathrm{rpm}$ for $15 \mathrm{~min}$. The serum samples of the same group were mixed well and heat-inactivated in a water bath at $56^{\circ} \mathrm{C}$ for $30 \mathrm{~min}$. Next, the serum sample was filtered through a $0.22-\mu \mathrm{m}$ membrane filter and stored at $-80^{\circ} \mathrm{C}$. 


\section{Identification and sorting of TEMs}

The bone marrow-derived macrophages (BMDMs) were isolated from the tumor-bearing mice (tumorbearing group, TB) and wild-type mice (normal group, NR). The MFC-bearing mouse model was established as described previously. After 2 weeks, the mice were sacrificed. The mouse skin was disinfected for 5 min using $75 \%$ ethanol. BMDM isolation was performed as previously described with minor modifications [16]. Femurs and tibias were excised from the mice under sterile conditions and the muscle tissues were removed carefully. The bone ends were cut and the marrow was flushed out using a syringe filled with DMEM into a small Petri dish. The supernatant was collected from the Petri dish and filtered through a $75-\mu \mathrm{m}$ membrane filter into $15-\mathrm{mL}$ tubes. The samples were centrifuged at $1000 \mathrm{rpm}$ and $4{ }^{\circ} \mathrm{C}$ for $10 \mathrm{~min}$. The supernatant was discarded and the pellet was incubated with $10 \mathrm{~mL}$ of red blood cell lysis buffer for $30 \mathrm{~s}$. Next, the pellet was resuspended in $10 \mathrm{~mL}$ of complete medium. The mixture was centrifuged at $1000 \mathrm{rpm}$ for $5 \mathrm{~min}$. The supernatant was removed and the pellet was resuspended in culture medium supplemented with $50 \mathrm{ng} / \mathrm{mL}$ macrophage colony-stimulating factor (MCSF) (RD systems, Minneapolis, MN, USA) and cultured for $72 \mathrm{~h}$. For flow cytometric analysis and cell sorting, the BMDMs were blocked with the whole lgG for 15 min at $4{ }^{\circ} \mathrm{C}$. The samples were immunostained with anti-CD45 (fluorescein isothiocyanate (FITC)-conjugated clone 30-F11) (Thermo Fisher Scientific, Waltham, MA, USA), anti-F4/80 (allophycocyanin (APC)-conjugated clone BM8), antiCD11b (APC/Cyanine7-conjugated clone M1/70), and anti-CD202b (TIE2) (phycoerythyrin (PE)conjugated clone TEK4) (all from BioLegend, San Diego, CA, USA). Flow cytometry analysis was performed using the Aria III flow cytometer.

\section{Cell migration assay}

Cell migration assay was performed using the Transwell plates with a pore size of $8 \mu \mathrm{m}$ (Corning, Cambridge, NY, USA). The TEMs $\left(2 \times 10^{5}\right)$ were seeded into the upper chamber. The bottom chamber was filled with the following three culture media supplemented with $300 \mathrm{ng} / \mathrm{mL}$ ANG-2 (R\&D systems, Minneapolis, MN, USA) which divided into the following three groups: the control medium group (CM); the blank serum-supplemented medium group (BSM), supplemented $10 \%$ serum derived from SD rats belonging to the blank serum group; the FZJD serum-supplemented medium group (FSM), supplemented $10 \%$ serum derived from SD rats belonging to the FZJD group. After $24 \mathrm{~h}$, the cells in the membrane were fixed, stained, and counted using light microscopy.

\section{Tube formation assay}

Briefly, Matrigel (BD Bioscience, San Diego, CA, USA) was added to the 24-well plates after thawing overnight. All plates were incubated at $4{ }^{\circ} \mathrm{C}$ for $30 \mathrm{~min}$ and $37^{\circ} \mathrm{C}$ for $30 \mathrm{~min}$ to allow gel polymerization.

The TEMs $\left(2 \times 10^{5} /\right.$ well $)$ and MAECs $\left(5 \times 10^{4} /\right.$ well $)$ were seeded on the gel. The cells were then incubated in CM, BSM and FSM (containing $200 \mathrm{ng} / \mathrm{mL}$ ANG-2) for $6 \mathrm{~h}$. Then stained with Calcein-AM (Solarbio, Beijing, China), and the number of capillary-like structures was counted using a fluorescence microscope.

\section{Quantitative real-time polymerase chain reaction (qRT-PCR) analysis}


The TEMs ( $2 \times 10^{5} /$ well) were seeded in CM, BSM and FSM (containing $200 \mathrm{ng} / \mathrm{mL}$ ANG-2) for $30 \mathrm{~min}$. Total RNA was extracted from the cells using TRIzol reagent (TIANGEN, Beijing, China), following the manufacturer's instructions. The concentration and purity of the RNA were determined using a ultraviolet (UV) spectrophotometer. The extracted RNA was reverse-transcribed into CDNA using the PrimeScript ${ }^{\text {TM }}$ RT reagent kit with gDNA Eraser (TaKaRa, Tokyo, Japan). The primers used for qRT-PCR analysis are listed in Table 1. The expression levels of target genes were normalized to those of Gapdh. The fold changes in gene expression were calculated using the $2^{-\Delta \Delta C t}$ method.

\section{Table 1 Primers used for qRT-PCR}

\begin{tabular}{|ll|}
\hline Primer name & Primer sequence \\
\hline Vegfa & \\
\hline Forward & 5'-ACACATTGTTGGAAGAAGCAGCCC-3' \\
\hline Reverse & 5'-AGGAAGGTCAACCACTCACACACA-3' \\
\hline Mmp9 & \\
\hline Forward & 5'-TGGGGGTTAGGGACAGAAAT-3' \\
\hline Reverse & 5'-GAACAATAACGCACAGACCC-3' \\
\hline Cox2 & \\
\hline Forward & 5'-CCAGAGCAGAGAGATGAAA-3' \\
\hline Reverse & 5'-GGTACAGTTCCATGACATC-3' \\
\hline Gapdh & \\
\hline Forward & 5'-TTCCTACCCCCAATGTATCCG-3' \\
\hline Reverse & 5'-CCACCCTGTTGCTGTAGCCATA-3' \\
\hline
\end{tabular}

\section{Immunohistofluorescence (IHF) staining}

IHF staining was performed using the $10-\mu \mathrm{m}$ thick paraformaldehyde-fixed tumor tissue sections. The sections were incubated with anti-TIE2 (rabbit anti-mouse, ab95722, 1:50; Abcam, Cambridge, UK) and anti-CD31 (goat anti-mouse, AF3628-SP, 1:100) (R\&D Systems, Minneapolis, MN, USA) primary antibodies. Next, the sections were incubated with Alexa Fluor 488-conjugated goat anti-rabbit (A-11008) and Alexa Fluor 555-conjugated donkey anti-goat antibodies (A-21432) (Thermo Fisher Scientific, Waltham, MA, USA). The nuclei were stained with 4',6-diamidino-2-phenylindole. Images were captured 
using a NIKON TE-2000U inverted fluorescence microscope. All images were processed identically using Adobe Photoshop CC2019 software.

\section{Statistical analysis}

All statistical analyses were performed using SPSS 18.0. The data are presented as mean \pm standard deviation. One-way analysis of variance (ANOVA) was used for multiple comparisons. Student's $t$ test was for analyzing unpaired data. The differences were considered significant at $P<0.05$.

\section{Results}

\section{Composition of the FZJD preparation}

As shown in Table 2 (see in the below of this article), sixteen bioactive components were identified in the eight herbs of FZJD. The concentration of each bioactive component ranged from $0.001 \mathrm{mg} / \mathrm{g}$ to 91.56 $\mathrm{mg} / \mathrm{g}$. Saccharides were the predominant component of FZJD. Additionally, FZJD contained high amounts of gallic acid, 2,3,5,4' tetrahydroxystilbene 2-0- $\beta$-D glucoside, betaine, and calycosin-7-glucoside.

Table 2 The effective ingredients in FZJD ointment $(n=3)$ 


\begin{tabular}{|c|c|c|c|}
\hline Herbs/Saccharides & Chemical constituents & $\begin{array}{l}\text { Chemical } \\
\text { formula }\end{array}$ & $\begin{array}{l}\text { Content }(\mathrm{mg} / \mathrm{g})=(\text { mean } \\
\pm \text { standard deviation })\end{array}$ \\
\hline \multirow{2}{*}{$\begin{array}{l}\text { Hedysarum multijugum } \\
\text { Maxim }\end{array}$} & calycosin-7-glucoside & $\mathrm{C}_{22} \mathrm{H}_{22} \mathrm{O}_{10}$ & $0.23 \pm 0.0015$ \\
\hline & astragaloside IV & $\mathrm{C}_{41} \mathrm{H}_{68} \mathrm{O}_{14}$ & / \\
\hline \multirow{4}{*}{$\begin{array}{l}\text { Fallopia multiflora } \\
\text { (Thunberg) Harald }\end{array}$} & Rhein & $\mathrm{C}_{15} \mathrm{H}_{8} \mathrm{O}_{6}$ & $0.0012 \pm 0.00$ \\
\hline & emodin & $\mathrm{C}_{15} \mathrm{H}_{10} \mathrm{O}_{5}$ & $0.03 \pm 0.0003$ \\
\hline & physcion & $\mathrm{C}_{16} \mathrm{H}_{12} \mathrm{O}_{5}$ & $0.01 \pm 0.0002$ \\
\hline & $\begin{array}{l}2,3,5,4 \text { ' } \\
\text { tetrahydroxystilbene 2-0- } \\
\beta-D \text { glucoside }\end{array}$ & $\mathrm{C}_{20} \mathrm{H}_{22} \mathrm{O}_{9}$ & $0.73 \pm 0.0161$ \\
\hline Bistortae Rhizoma & gallic acid & $\mathrm{C}_{7} \mathrm{H}_{6} \mathrm{O}_{5}$ & $0.81 \pm 0.0064$ \\
\hline $\begin{array}{l}\text { Actinidia arguta (Siebold \& } \\
\text { Zucc,) Planch. ex Miq.B }\end{array}$ & epicatechin & $\mathrm{C}_{15} \mathrm{H}_{14} \mathrm{O}_{6}$ & $0.05 \pm 0.0025$ \\
\hline Smilacis Glabrae Rhizoma & astilbin & $\mathrm{C}_{21} \mathrm{H}_{22} \mathrm{O}_{11}$ & $0.12 \pm 0.0018$ \\
\hline Codonopsis Radix & lobetyolin & $\mathrm{C}_{20} \mathrm{H}_{28} \mathrm{O}_{8}$ & $0.07 \pm 0.0014$ \\
\hline Fructus Lycii & betaine & $\mathrm{C}_{5} \mathrm{H}_{11} \mathrm{NO}_{2}$ & $0.06 \pm 0.0477$ \\
\hline \multirow{3}{*}{$\begin{array}{l}\text { Atractylodes macrocephala } \\
\text { Koidz }\end{array}$} & atractylenolide $\otimes$ & $\mathrm{C}_{15} \mathrm{H}_{18} \mathrm{O}_{2}$ & $0.001 \pm 0.00$ \\
\hline & 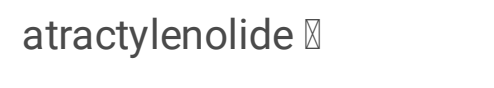 & $\mathrm{C}_{15} \mathrm{H}_{20} \mathrm{O}_{2}$ & $0.0089 \pm 0.0003$ \\
\hline & 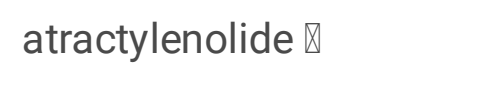 & $\mathrm{C}_{15} \mathrm{H}_{20} \mathrm{O}_{3}$ & $0.0093 \pm 0.0001$ \\
\hline \multirow[t]{3}{*}{ Saccharides } & fructose & $\mathrm{C}_{6} \mathrm{H}_{12} \mathrm{O}_{6}$ & $91.56 \pm 1.25$ \\
\hline & glucose & $\mathrm{C}_{6} \mathrm{H}_{12} \mathrm{O}_{6}$ & $57.85 \pm 0.45$ \\
\hline & sucrose & $\mathrm{C}_{12} \mathrm{H}_{22} \mathrm{O}_{11}$ & $74.67 \pm 0.76$ \\
\hline
\end{tabular}

\section{BMDMs from tumor-bearing mice comprised a high proportion of TEMs}

Forget et al. reported that M-CSF promotes TIE2 expression in the monocytes [17]. The BMDMs isolated from different groups of mice were subjected to flow cytometric analysis. The sequential gating strategy for TEMs enumeration is presented in Figure 1a. At baseline, there was no significant difference in the proportion of $\mathrm{CD} 45^{+} \mathrm{F} 4 / 80^{+} \mathrm{CD} 11 \mathrm{~b}^{+} \mathrm{BMDMs}$ between NR and TB. The percentage of $\mathrm{CD} 45^{+} \mathrm{F} 4 / 80^{+} \mathrm{CD} 11 \mathrm{~b}^{+} \mathrm{CD} 202 \mathrm{~b}^{+}$TEMs in the TB $(35.82 \pm 6.4 \%)$ was significantly higher than that in the NR 
$(9.34 \pm 0.34 \%)(P<0.0001)$ (Figure 1b). The TEMs were sorted from the BMDMs of the TB for further experiments.

\section{FZJD inhibits the migration of TEMs in vitro}

The effect of FZJD on the migration of TEMs was examined. As shown in Figures $2 \mathrm{a}$ and $\mathrm{b}$, the migration of TEMs in FSM $(73.7 \pm 5.5)$ was significantly lower than that in CM $(110 \pm 12)(P<0.0001)$. The migration of TEMs was not significantly different between BSM and CM $(99 \pm 8)(P>0.05)$. These findings indicated that FZJD inhibits the migration of TEMs in vitro.

\section{FZJD inhibits the pro-angiogenic activity of TEMs in vitro}

Next, the effect of FZJD on the pro-angiogenic activity of TEMs was examined. As shown in Figures 3 a and $b$, the number of capillary-like structures in FSM $(15.6 \pm 2.6)$ was significantly lower than that in CM $(24.2 \pm 3.7)(P<0.001)$. In contrast, the number of capillary-like structures was not significantly different BSM $(22.2 \pm 3.42)$ and CM $(P>0.05)$. The qRT-PCR analysis revealed that the mRNA levels of Vegfa, Mmp9, and Cox2 in the FSM were significantly downregulated when compared with those in the CM. In contrast, the mRNA levels of Vegfa, Mmp9, and Cox2 were not significantly different between BSM and $\mathrm{CM}$ (Figure 3c). These findings indicate that FZJD inhibits the pro-angiogenic activity of TEMs in vitro.

\section{FZJD enhances the therapeutic efficacy of 5-FU by inhibiting TEM-mediated angiogenesis in vivo}

The anti-tumor activity of FZJD was examined using the tumor-bearing mouse model. As shown in Figures $4 \mathrm{a}$ and $\mathrm{b}$, the average weight of tumors excised from the control group $(1.32 \pm 0.24 \mathrm{~g})$ was significantly higher than that of tumors excised from the FZJD $(0.87 \pm 0.28 \mathrm{~g} ; P<0.01)$ and 5-FU groups $(0.73 \pm 0.20 \mathrm{~g} ; P<0.0001)$. Compared with that in the FZJD $(P<0.01)$ and 5 -FU $(P<0.05)$ groups, the tumor growth was significantly lower in the FZJD+5-FU group.

TEMs are preferentially localized in the perivascular region of the tumor tissues to facilitate tumor angiogenesis [18]. The tumor sections were immunostained with anti-TIE-2 and anti-CD31 antibodies, which enables the identification of TEMs and endothelial cells (ECs), respectively, to evaluate the role of TEMs in the anti-tumor activity of FZJD. As shown in Figure $4 \mathrm{c}$, there was no significant difference in the number of infiltrated TEMs between the control, 5-FU, FZJD, and FZJD+5-FU groups $(P>0.05)$. The FZJD group did not exhibit a decreased EC population. In contrast, the EC population in FZJD+5-FU group was significantly smaller than that in the control, 5-FU, and FZJD groups $(P<0.0001)$ (Figure $4 \mathrm{~d}$ ). This suggested that FZJD alone does not inhibit the migration and pro-angiogenic activity of TEMs in vivo but suppressed angiogenesis in combination with 5-FU. Thus, FZJD improved the therapeutic efficacy of 5-FU by inhibiting TEM-mediated angiogenesis.

\section{Discussion}

In 1971, Folkman first highlighted the significance of vasculature in solid tumor growth [19]. TEMs, which are considerate as the most pro-angiogenic subtypes of TAMs[20], provide therapeutic opportunity for GC. 
The strategies for targeting TEMs have been reviewed elsewhere [21], including selectively disrupts the interaction between ANG-2 and TIE-2. For example, AMG 386 is a peptide that prevents the binding of ANG-1 and ANG-2 to TIE-2 [22]. In a Phase I clinical trial [23], treatment with the combination of AMG 386 and chemotherapy drugs exhibited promising anti-tumor activity against advanced solid tumors.

However, the progression-free survival (PFS) and objective response rate (ORR) of patients with advanced GC treated with the combination of AMG 386, cisplatin, and capecitabine were similar to those of the placebo group in a Phase II clinical trial [24]. According to TRINOVA-3, AMG 386 plus carboplatin and paclitaxel did not improve PFS in advanced ovarian cancer patients as first-line treatment [25]. Various challenges remained to be addressed for clinical application of these strategies. Hence, there is a need to develop complementary and alternative strategies. The anti-tumor effect of herbs used in traditional Chinese medicine (TCM) is mediated through various mechanisms, including modulation of the tumor microenvironment (TME) [26]. The herbs used in TCM are also reported to regulate TAMs [27-29]. However, there are limited studies on the effect of TCM herbs on TEMs.

Previous studies have isolated TEMs from the peripheral blood and/or tumor tissues of mice [17, 30]. In this, the TEMs were obtained by culturing the BMDMs in M-CSF-supplemented medium. M-CSF is essential for myeloid cell growth, survival, and differentiation [31]. The flow cytometric analysis revealed that the differentiation of BMDMs into TEMs in tumor-bearing mice was higher than that in wild-type mice. It is estimated that there are approximately $60 \times 10^{6}$ bone marrow cells in each mouse from which $30 \times 10^{6} \mathrm{BMDMs}$ are generated [32]. The method established in this study enables the isolation of a large number of TEMs. In this study, FZJD inhibited the migration and pro-angiogenic activity of TEMs in vitro. However, FZJD did not decrease the number of TEMs and ECs in the tumor tissues. The treatment combination of FZJD and 5-FU did not inhibit the accumulation of TEMs in the tumor tissues. However, the number of ECs was significantly low in the tumor tissues of the FZJD+5-FU group, which suggested that FZJD enhanced the therapeutic efficacy of 5-FU through the regulation of TEMs.

There were several limitations in our present study. At first, we did not explore the effect of FZJD to hypoxia in tumor as hypoxia may explain the inconsistent findings between our in vitro and in vivo results. Hypoxia is a myeloid cell recruiting signal and reported to promote TIE-2 receptor expression in the myeloid cells [33]. Chen et al. demonstrated that TIE-2 expression was markedly upregulated in the mouse circulatory $\mathrm{CD} 11 \mathrm{~b}^{+} \mathrm{Ly} 6 \mathrm{C}^{+}$cells under hypoxic conditions in vitro [34]. Additionally, treatment with doxorubicin significantly upregulated HIF-1a expression in the tumor tissues. HIF-1a promoted the recruitment of TIE-2-expressing $\mathrm{CD} 11 \mathrm{~b}^{+} \mathrm{Ly} 6 \mathrm{C}^{+}$cells to the tumors, which enhanced vascular regrowth and tumor relapse. Moreover, ANG-2 is the target gene of HIF-1 a [35]. Thus, it can be speculated that FZJD regulates the function of TEMs through the attenuation of 5-FU-induced hypoxia. Several studies have reported a correlation between FZJD components and hypoxia. Kim et al. demonstrated that betaine, a phytochemical component of FZJD, attenuated VEGF and HIF-1a expression through the suppression of the AKT pathway [36]. Rhein, another phytochemical component of FZJD, inhibits VEGF and HIF-1a expression in the human breast cells under normoxic or hypoxic conditions [37]. Another shortcoming of our work is that we did not investigate the effect of FZJD to the downstream signal pathways of 
Ang2/Tie2, such as PI3K/AKT pathway[38]. Further studies are needed to elucidate the mechanism underlying the anti-cancer activity of FZJD.

\section{Conclusions}

This study presented a new method to obtain TEMs from mice. The synergistic therapeutic effect of FZJD and 5-FU may be related to the inhibition of TEM-mediated angiogenesis.

\section{Abbreviations}

GC: gastric cancer;

5-FU: 5-fluoropyrimidine;

TEMs: TIE2-expressing monocytes/macrophages;

TAMs: tumor-associated macrophages;

ANGs: Angiopoietins;

FZJD: Fu-Zheng-Jie-Du ointment;

HPLC: High-performance liquid chromatography;

MFC: Mouse forestomach carcinoma cell;

MAEC: Mouse aorta endothelial cell;

DMEM: Dulbecco's modified Eagle medium;

PBS: Phosphate-buffered saline;

OG: Oral gavage;

BMDMs: Bone marrow-derived macrophages;

TB: Tumor-bearing group;

NR: Normal group;

M-CSF: Macrophage colony-stimulating factor;

FITC: Fluorescein isothiocyanate;

APC: Allophycocyanin; 
PE: Phycoerythyrin;

CM: The control medium group $\rrbracket$

BSM: The blank serum-supplemented medium group;

FSM: The FZJD serum-supplemented medium group;

qRT-PCR: Quantitative real-time polymerase chain reaction;

UV: Ultraviolet;

IHF: Immunohistofluorescence;

ANOVA: One-way analysis of variance;

ECs: Endothelial cells;

TCM: Traditional Chinese Medicine;

TME: Tumor microenvironment.

\section{Declarations}

\section{Ethics approval and consent to participate}

The study on animals was approved by Ethical Committee of Guang'anmen Hospital, China Academy of Chinese Medical Sciences, Beijing.

\section{Consent for publication}

Not applicable

\section{Availability of data and materials}

The datasets used and/or analyzed during the current study are available from the corresponding author on reasonable request.

\section{Competing interests}

The authors declare that they have no competing interest.

\section{Funding}

This work was supported by grants from the national natural science foundation of China (81473463).

\section{Authors' contributions}


$\mathrm{JL}$ conceived and designed the work; ZW wrote the manuscript; RKG and MMX performed the experiments and collected samples; ZW, RKG and MMX both acted as first authors; ZS and QHT participated in data collection and analysis.

\section{Acknowledgments}

Not applicable

\section{Authors' information}

${ }^{1}$ China Academy of Chinese Medical Science, Beijing, 100700, China. ${ }^{2}$ Shaanxi University of Chinese Medicine, Xi'an, Shaanxi, 712046, China. ${ }^{3}$ Department of Oncology, Guang'anmen Hospital, China Academy of Chinese Medical Sciences, Beijing, 10053, China.

\section{References}

1. Feng RM, Zong YN, Cao SM, Xu RH. Current cancer situation in China: good or bad news from the 2018 Global Cancer Statistics? Cancer Commun (Lond). 2019; 39(1):22. http://dx.doi.org/10.1186/s40880-019-0368-6

2. Song Z, Wu Y, Yang J, Yang D, Fang X. Progress in the treatment of advanced gastric cancer. Tumour Biol. 2017; 39(7):1010428317714626.http://dx.doi.org/10.1177/1010428317714626

3. Selim JH, Shaheen S, Sheu WC, Hsueh CT. Targeted and novel therapy in advanced gastric cancer. Exp Hematol Oncol. 2019;8:25. http://dx.doi.org/10.1186/s40164-019-0149-6

4. Chen Y, Song Y, Du W, Gong L, Chang H, Zou Z. Tumor-associated macrophages: an accomplice in solid tumor progression. J Biomed Sci. 2019; 26(1):78. http://dx.doi.org/10.1186/s12929-019-0568$z$

5. De Palma M, Venneri MA, Galli R, Sergi Sergi L, Politi LS, Sampaolesi M, Naldini L. Tie2 identifies a hematopoietic lineage of proangiogenic monocytes required for tumor vessel formation and a mesenchymal population of pericyte progenitors. Cancer Cell 2005, 8(3):211-226. http://dx.doi.org/10.1016/j.ccr.2005.08.002

6. Goede V, Coutelle O, Shimabukuro-Vornhagen A, Holtick U, Neuneier J, Koslowsky TC, Weihrauch MR, von Bergwelt-Baildon M, Hacker UT: Analysis of Tie2-expressing monocytes (TEM) in patients with colorectal cancer. Cancer Invest. 2012; 30(3):225-230. http://dx.doi.org/10.3109/07357907.2011.636114

7. De Palma M, Coukos G, Semela D. TIE2-expressing monocytes: a novel cellular biomarker for hepatocellular carcinoma? Hepatology. 2013;57(4):1294-1296. http://dx.doi.org/10.1002/hep.26025

8. Ji J, Zhang G, Sun B, Yuan H, Huang Y, Zhang J, Wei X, Zhang X, Hou J. The frequency of tumorinfiltrating Tie-2-expressing monocytes in renal cell carcinoma: its relationship to angiogenesis and progression. Urology. 2013; 82(4):974.e979-913. http://dx.doi.org/10.1016/j.urology.2013.05.026 
9. Yang WJ, Hao YX, Yang X, Fu XL, Shi Y, Yue HL, Yin P, Dong HL, Yu PW. Overexpression of Tie2 is associated with poor prognosis in patients with gastric cancer. Oncol Lett. 2018; 15(5):8027-8033. http://dx.doi.org/10.3892/ol.2018.8329

10. Asahara T, Chen D, Takahashi T, Fujikawa K, Kearney M, Magner M, Yancopoulos GD, Isner JM. Tie2 receptor ligands, angiopoietin-1 and angiopoietin-2, modulate VEGF-induced postnatal neovascularization. Circ Res. 1998; 83(3):233-240. http://dx.doi.org/10.1161/01.res.83.3.233

11. Xuan ZX, Zhang S, Yuan SJ, Wang W, Yu J. Prognostic value of angiopoietin-2 in non-small cell lung cancer patients: a meta-analysis. World J Surg Oncol. 2016; 14(1):237.

http://dx.doi.org/10.1186/s12957-016-0992-4

12. Wang H, Hang C, Ou XL, Nie JS, Ding YT, Xue SG, Gao H, Zhu JX: MiR-145 functions as a tumor suppressor via regulating angiopoietin-2 in pancreatic cancer cells. Cancer Cell Int. 2016; $16(1): 65$. http://dx.doi.org/10.1186/s12935-016-0331-4

13. Chen Y, Wu Y, Zhang X, Zeng H, Liu Y, Wu Q, Chen Y, Zhu G, Pan Q, Jin L et al. Angiopoietin-2 (Ang-2) is a useful serum tumor marker for liver cancer in the Chinese population. Clin Chim Acta. 2018; 478:18-27. http://dx.doi.org/10.1016/j.cca.2017.12.017

14. Coffelt SB, Tal AO, Scholz A, De Palma M, Patel S, Urbich C, Biswas SK, Murdoch C, Plate KH, Reiss Y et al. Angiopoietin-2 regulates gene expression in TIE2-expressing monocytes and augments their inherent proangiogenic functions. Cancer Res. 2010; 70(13):5270-5280.

http://dx.doi.org/10.1016/j.cca.2017.12.017

15. Jia CH, Li FF. The Effect of Fuzheng Jiedu Formula on Tumor Associated Macrophage and Related Cytokine in the Mouse Gastric Cancer Postoperative Recurrence Model. Chinese Journal of Basic Medicine in Traditional Chinese Medicine. 2014; 20(6):748-751.

16. Trouplin V, Boucherit N, Gorvel L, Conti F, Mottola G, Ghigo E. Bone marrow-derived macrophage production. J Vis Exp. 2013; (81):e50966. http://dx.doi.org/10.3791/50966

17. Forget MA, Voorhees JL, Cole SL, Dakhlallah D, Patterson IL, Gross AC, Moldovan L, Mo X, Evans R, Marsh CB et al. Macrophage colony-stimulating factor augments Tie2-expressing monocyte differentiation, angiogenic function, and recruitment in a mouse model of breast cancer. PLoS One. 2014; 9(6):e98623. http://dx.doi.org/10.1371/journal.pone.0098623

18. Lewis CE, Harney AS, Pollard JW. The Multifaceted Role of Perivascular Macrophages in Tumors. Cancer Cell. 2016;30(2):365. http://dx.doi.org/10.1016/j.ccell.2016.07.009

19. Folkman J. Tumor angiogenesis: therapeutic implications. N Engl J Med. 1971;285(21):1182-1186.

20. Venneri MA, De Palma M, Ponzoni M, Pucci F, Scielzo C, Zonari E, Mazzieri R, Doglioni C, Naldini L. Identification of proangiogenic TIE2-expressing monocytes (TEMs) in human peripheral blood and cancer. Blood. 2007; 109(12):5276-5285. http://dx.doi.org/10.1016/j.ccr.2005.08.002

21. Turrini R, Pabois A, Xenarios I, Coukos G, Delaloye JF, Doucey MA. TIE-2 expressing monocytes in human cancers. Oncoimmunology. 2017;6(4):e1303585. http://dx.doi.org/

$10.1080 / 2162402 X .2017 .1303585$

Page $14 / 21$ 
22. Herbst RS, Hong D, Chap L, Kurzrock R, Jackson E, Silverman JM, Rasmussen E, Sun YN, Zhong D, Hwang YC et al. Safety, pharmacokinetics, and antitumor activity of AMG 386, a selective angiopoietin inhibitor, in adult patients with advanced solid tumors. J Clin Oncol. 2009; 27(21):35573565. http://dx.doi.org/ 10.1200/JCO.2008.19.6683

23. Mita AC, Takimoto CH, Mita M, Tolcher A, Sankhala K, Sarantopoulos J, Valdivieso M, Wood L, Rasmussen E, Sun YN et al. Phase 1 study of AMG 386, a selective angiopoietin 1/2-neutralizing peptibody, in combination with chemotherapy in adults with advanced solid tumors. Clin Cancer Res. 2010; 16(11):3044-3056.http://dx.doi.org/10.1158/1078-0432.CCR-09-3368

24. Peeters M, Strickland AH, Lichinitser M, Suresh AV, Manikhas G, Shapiro J, Rogowski W, Huang X, Wu $B$, Warner $D$ et al. A randomised, double-blind, placebo-controlled phase 2 study of trebananib (AMG 386) in combination with FOLFIRI in patients with previously treated metastatic colorectal carcinoma. Br J Cancer. 2013; 108(3):503-511. http://dx.doi.org/ 10.1038/bjc.2012.594

25. Vergote I, Scambia G, O'Malley DM, Van Calster B, Park SY, Del Campo JM, Meier W, Bamias A, Colombo N, Wenham RM et al. Trebananib or placebo plus carboplatin and paclitaxel as first-line treatment for advanced ovarian cancer (TRINOVA-3/ENGOT-ov2/GOG-3001): a randomised, doubleblind, phase 3 trial. Lancet Oncol. 2019;20(6):862-876. http://dx.doi.org/10.1016/S14702045(19)30178-0

26. He J, Yin P, Xu K. Effect and Molecular Mechanisms of Traditional Chinese Medicine on Tumor Targeting Tumor-Associated Macrophages. Drug Des Devel Ther. 2020;14:907-919. http://dx.doi.org/10.2147/DDDT.S223646

27. Piao M, Cao H, He N, Yang B, Dong W, Xu M, Yan F, Zhou B, Wang B. Berberine Inhibits Intestinal Polyps Growth in Apc (min/+) Mice via Regulation of Macrophage Polarization. Evid Based Complement Alternat Med. 2016; 2016:5137505. http://dx.doi.org/ 10.1155/2016/5137505

28. Wang B, Zheng X, Liu J, Zhang Z, Qiu C, Yang L, Zhang L, Zhang Q, Gao H, Wang X. Osthole inhibits pancreatic cancer progression by directly exerting negative effects on cancer cells and attenuating tumor-infiltrating M2 macrophages. J Pharmacol Sci. 2018;137(3):290-298. http://dx.doi.org/10.1016/j.jphs.2018.07.007

29. Zhao X, Qu J, Liu X, Wang J, Ma X, Zhao X, Yang Q, Yan W, Zhao Z, Hui Y et al. Baicalein suppress EMT of breast cancer by mediating tumor-associated macrophages polarization. Am J Cancer Res. 2018;8(8):1528-1540.

30. Pucci F, Venneri MA, Biziato D, Nonis A, Moi D, Sica A, Di Serio C, Naldini L, De Palma M. A distinguishing gene signature shared by tumor-infiltrating Tie2-expressing monocytes, blood "resident" monocytes, and embryonic macrophages suggests common functions and developmental relationships. Blood. 2009;114(4):901-914.http://dx.doi.org/10.1182/blood-2009-01-200931

31. Lee AW, States DJ. Colony-stimulating factor-1 requires PI3-kinase-mediated metabolism for proliferation and survival in myeloid cells. Cell Death Differ. 2006;13(11):1900-1914. http://dx.doi.org/10.1038/sj.cdd.4401884 
32. Assouvie A, Daley-Bauer LP, Rousselet G. Growing Murine Bone Marrow-Derived Macrophages. Methods Mol Biol. 2018;1784:29-33. http://dx.doi.org/10.1007/978-1-4939-7837-3_3

33. Murdoch C, Tazzyman S, Webster S, Lewis CE. Expression of Tie-2 by human monocytes and their responses to angiopoietin-2. J Immunol. 2007;178(11):7405-7411. http://dx.doi.org/ 10.4049/jimmunol.178.11.7405

34. Chen L, Li J, Wang F, Dai C, Wu F, Liu X, Li T, Glauben R, Zhang Y, Nie G et al. Tie2 Expression on Macrophages Is Required for Blood Vessel Reconstruction and Tumor Relapse after Chemotherapy. Cancer Res. 2016;76(23):6828-6838. http://dx.doi.org/10.1158/0008-5472.CAN-16-1114

35. Simon MP, Tournaire R, Pouyssegur J. The angiopoietin-2 gene of endothelial cells is up-regulated in hypoxia by a HIF binding site located in its first intron and by the central factors GATA-2 and Ets- 1 . J Cell Physiol. 2008;217(3):809-818. http://dx.doi.org/ 10.1002/jcp.21558

36. Kim YG, Lim HH, Lee SH, Shin MS, Kim CJ, Yang HJ. Betaine inhibits vascularization via suppression of Akt in the retinas of streptozotocin-induced hyperglycemic rats. Mol Med Rep. 2015;12(2):16391644. http://dx.doi.org/10.3892/mmr.2015.3613

37. Fernand VE, Losso JN, Truax RE, Villar EE, Bwambok DK, Fakayode SO, Lowry M, Warner IM. Rhein inhibits angiogenesis and the viability of hormone-dependent and -independent cancer cells under normoxic or hypoxic conditions in vitro. Chem Biol Interact. 2011;192(3):220-232. http://dx.doi.org/ 10.1016/j.cbi.2011.03.013

38. Akwii RG, Sajib MS, Zahra FT, Mikelis CM. Role of Angiopoietin-2 in Vascular Physiology and Pathophysiology. Cells. 2019; 8(5). http://dx.doi.org/10.3390/cells8050471

\section{Figures}


a
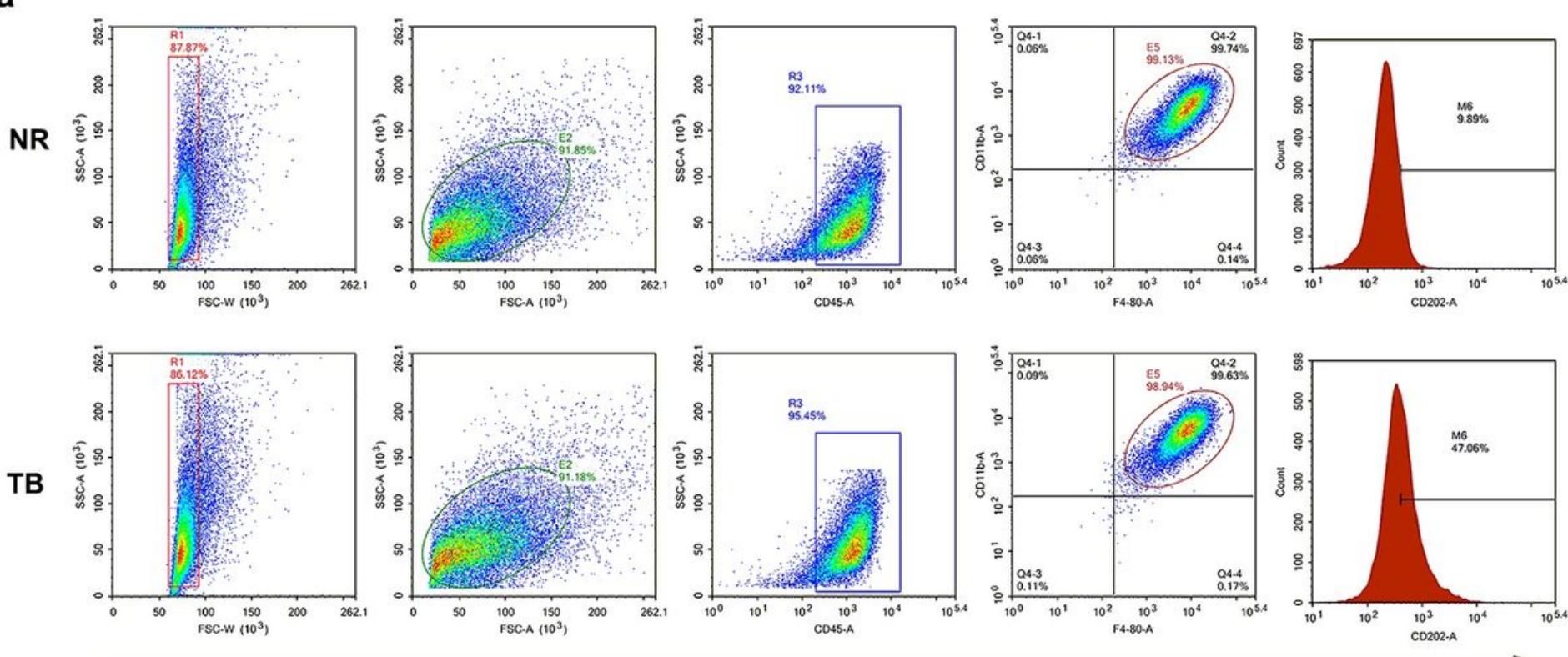

b

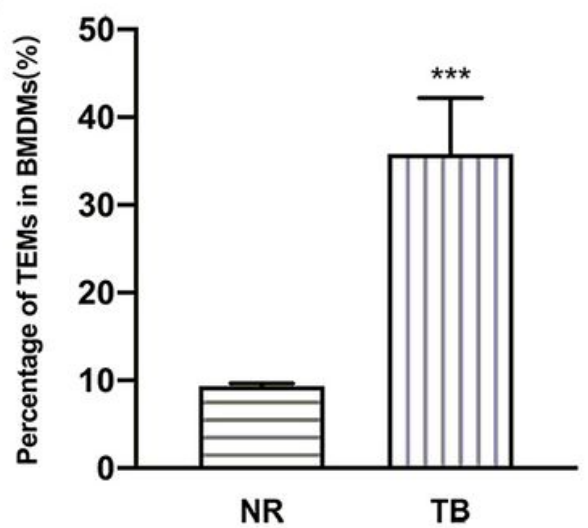

Figure 1

High proportion of TEMs was detected in the BMDMs derived from tumor-bearing mice. Percentage of $\mathrm{CD} 45+\mathrm{F} 4 / 80+\mathrm{CD} 11 \mathrm{~b}+\mathrm{CD} 202 \mathrm{~b}+\mathrm{TEMs}$ in the BMDMs derived from TB and NR. (a) The sequential gating strategy for TEM enumeration. (b) The quantification of the proportion of TEMs in the BMDMs. ${ }^{\star \star \star} \mathrm{P}<$ 0.0001 ; TB group vs. NR group $(n=6)$. 


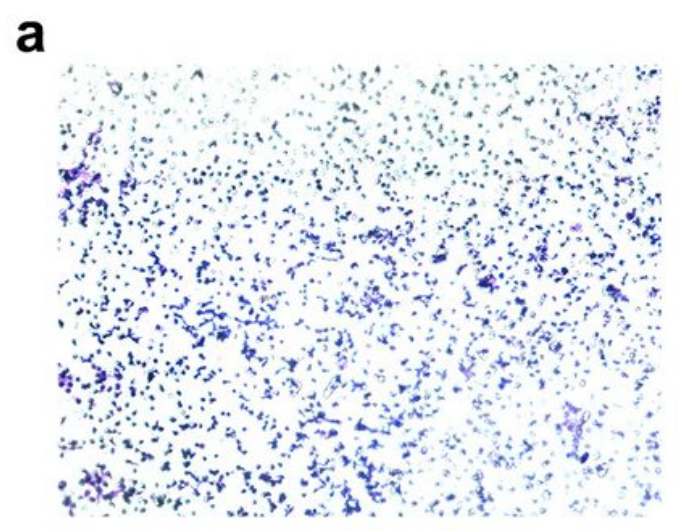

$\mathrm{CM}$

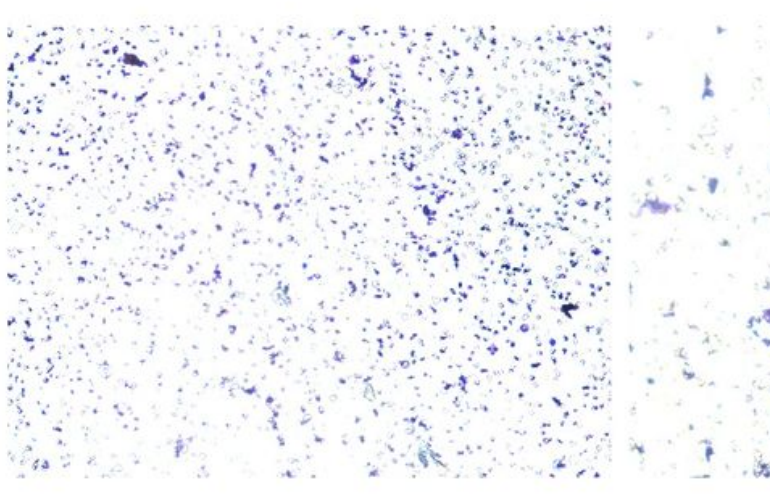

BSM

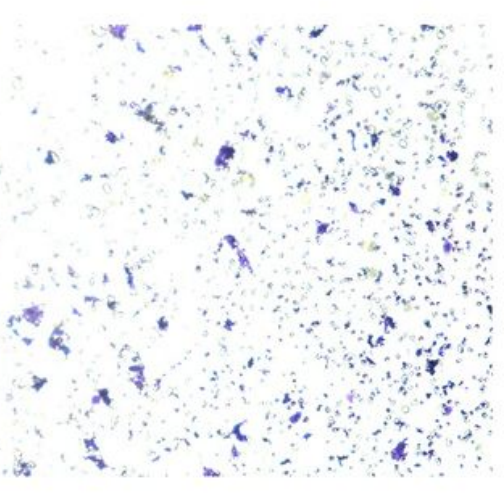

FSM

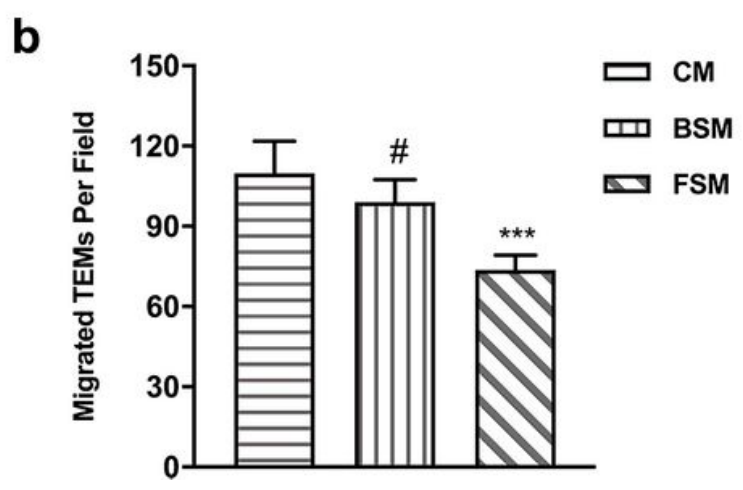

Figure 2

FZJD inhibits the migration of TEMs. The effect of FZJD on the migration of TEMs was examined using the Transwell assay. (a) The cells in each group were fixed and imaged. The number of migrated cells counted in five random fields of each well was averaged $(n=6)$. (b) Quantification of the migration assay results. ${ }^{\star * \star P}<0.0001, \mathrm{FSM}$ vs. CM; $\# \mathrm{P}>0.05, \mathrm{BSM}$ vs. $\mathrm{CM}$. Three independent experiments were performed. 
a

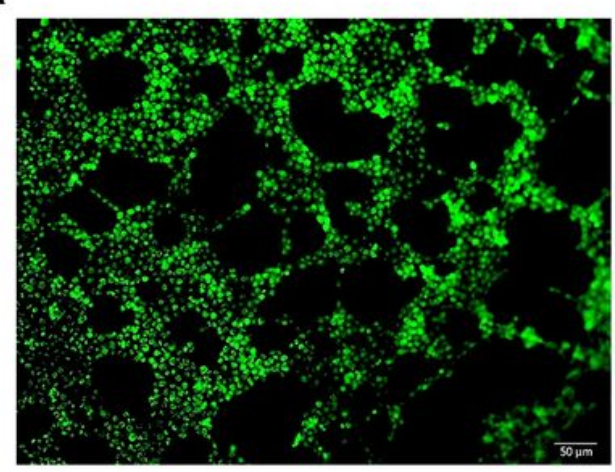

$\mathrm{CM}$

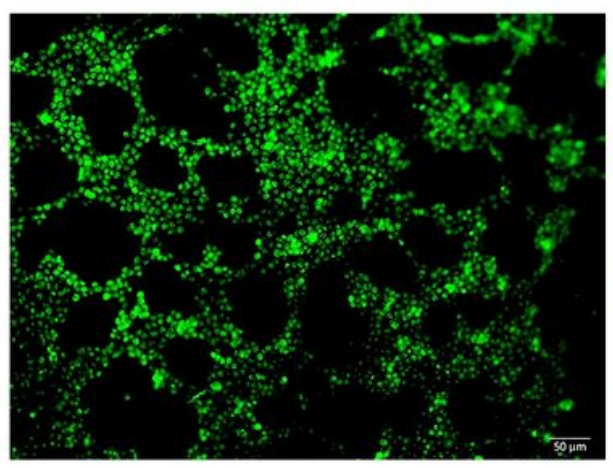

BSM

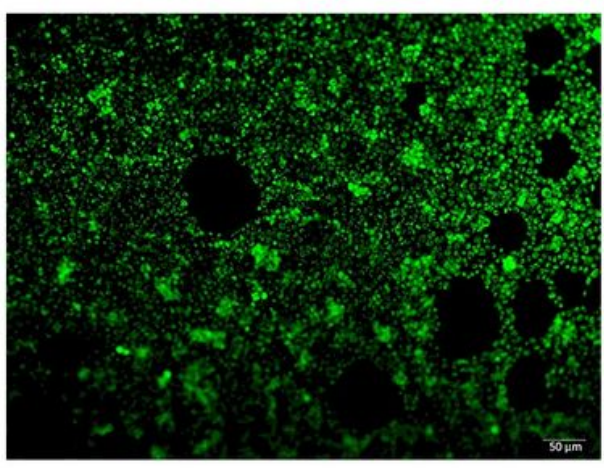

FSM

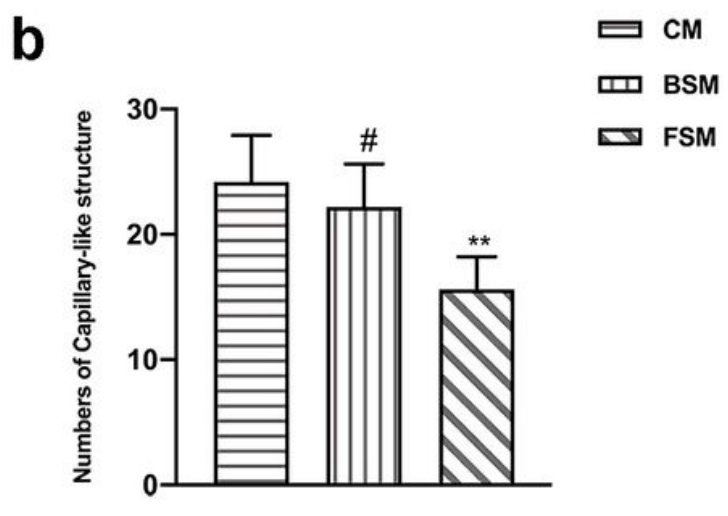

C
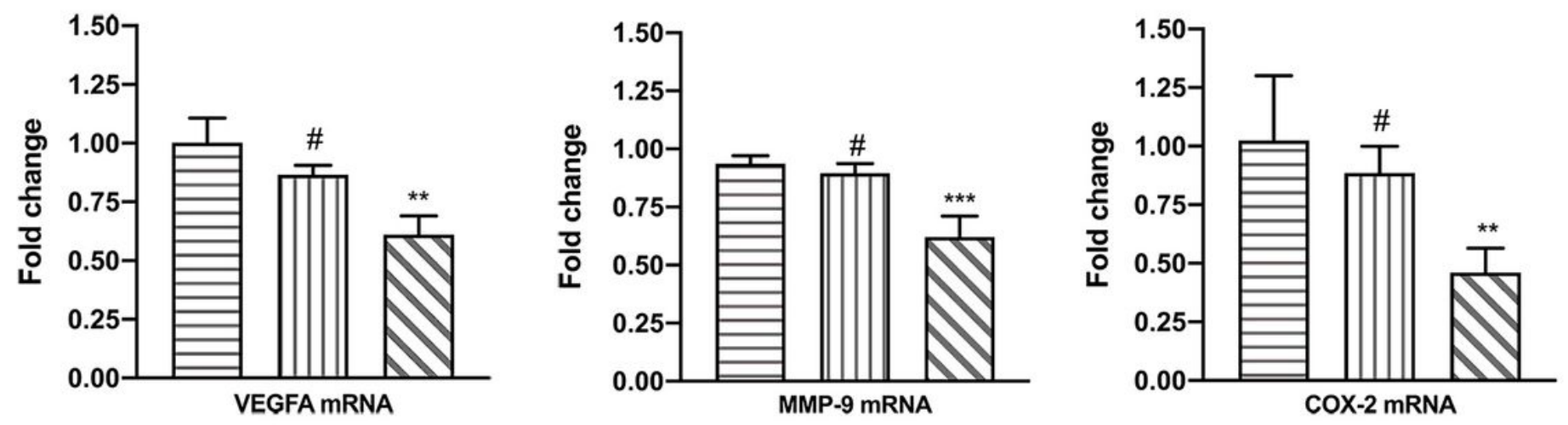

Figure 3

FZJD inhibits the pro-angiogenic activity of TEMs. The effect of FZJD on the pro-angiogenic activity of TEMs was evaluated using the tube formation and qRT-PCR assays. (a) TEMs and MAECs were cocultured on the gel for $6 \mathrm{~h}$, stained, and imaged. The number of capillary-like structures in five random fields of each well was averaged $(n=6)$. Scale bar, $50 \mu \mathrm{m}$. (b) Quantification of the tube formation assay results. ${ }^{*} P<0.01, F S M$ vs. BSM; \#P $>0.05$, BSM vs. CM. (c) Quantification of the qRT-PCR assays results. ${ }^{\star * \star} \mathrm{P}<0.0001, \mathrm{FSM}$ vs. CM; ${ }^{\star *} \mathrm{P}<0.01, \mathrm{FSM}$ vs. BSM; \#P $>0.05, \mathrm{BSM}$ vs. CM. Three independent experiments were performed. 
a

\section{Control}

FZJD

5-FU

FZJD+5-FU

C

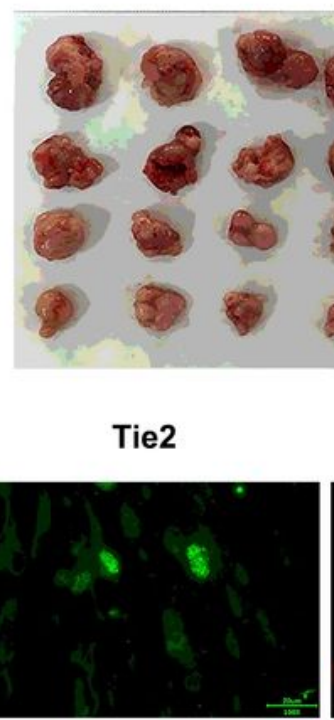

a 0
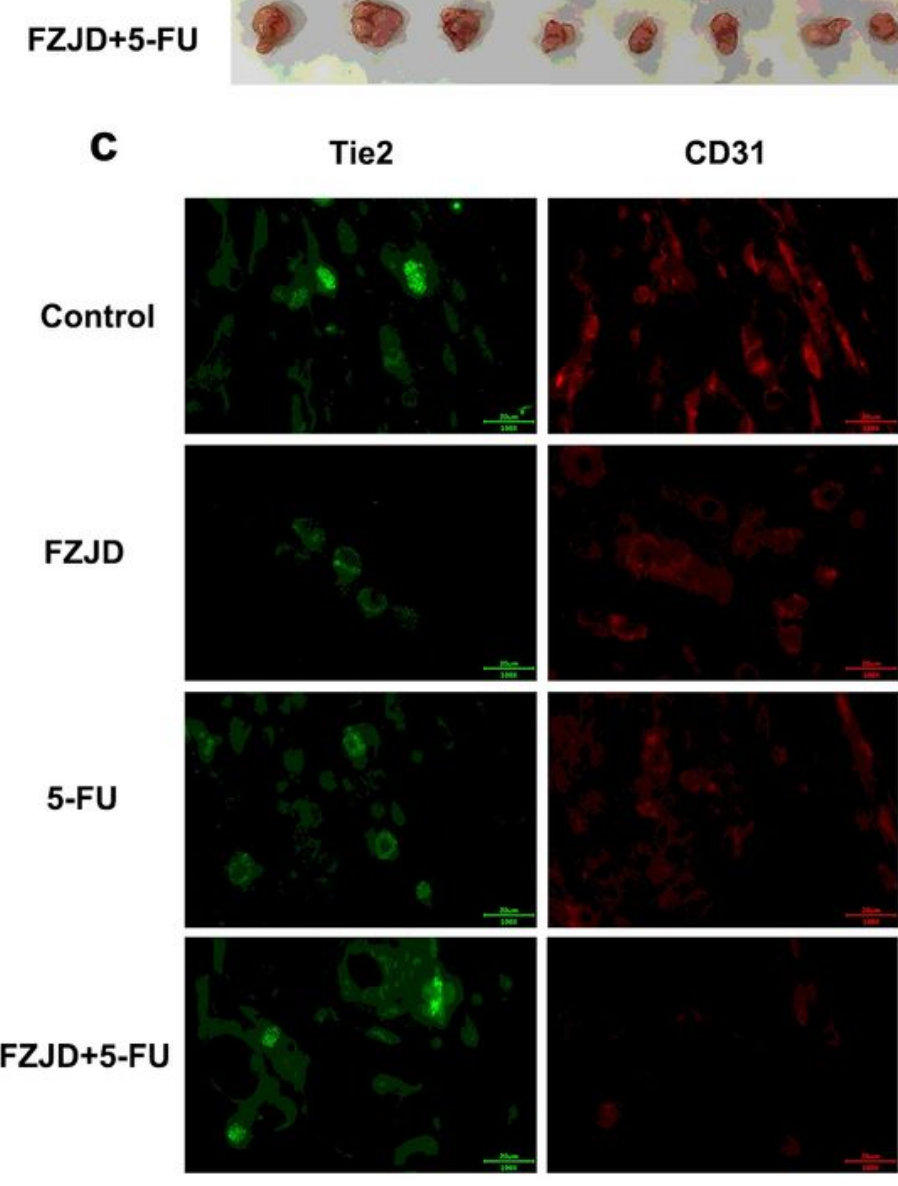

d

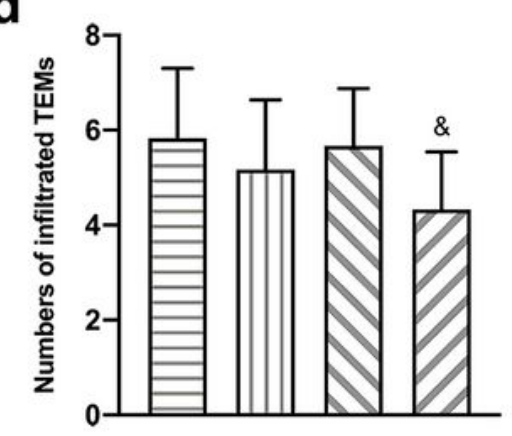

b

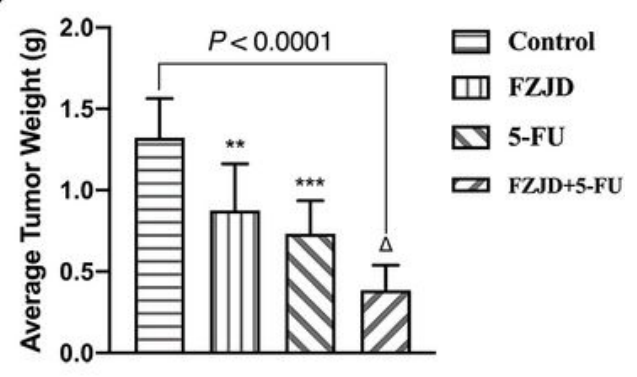

DAPI

Merge
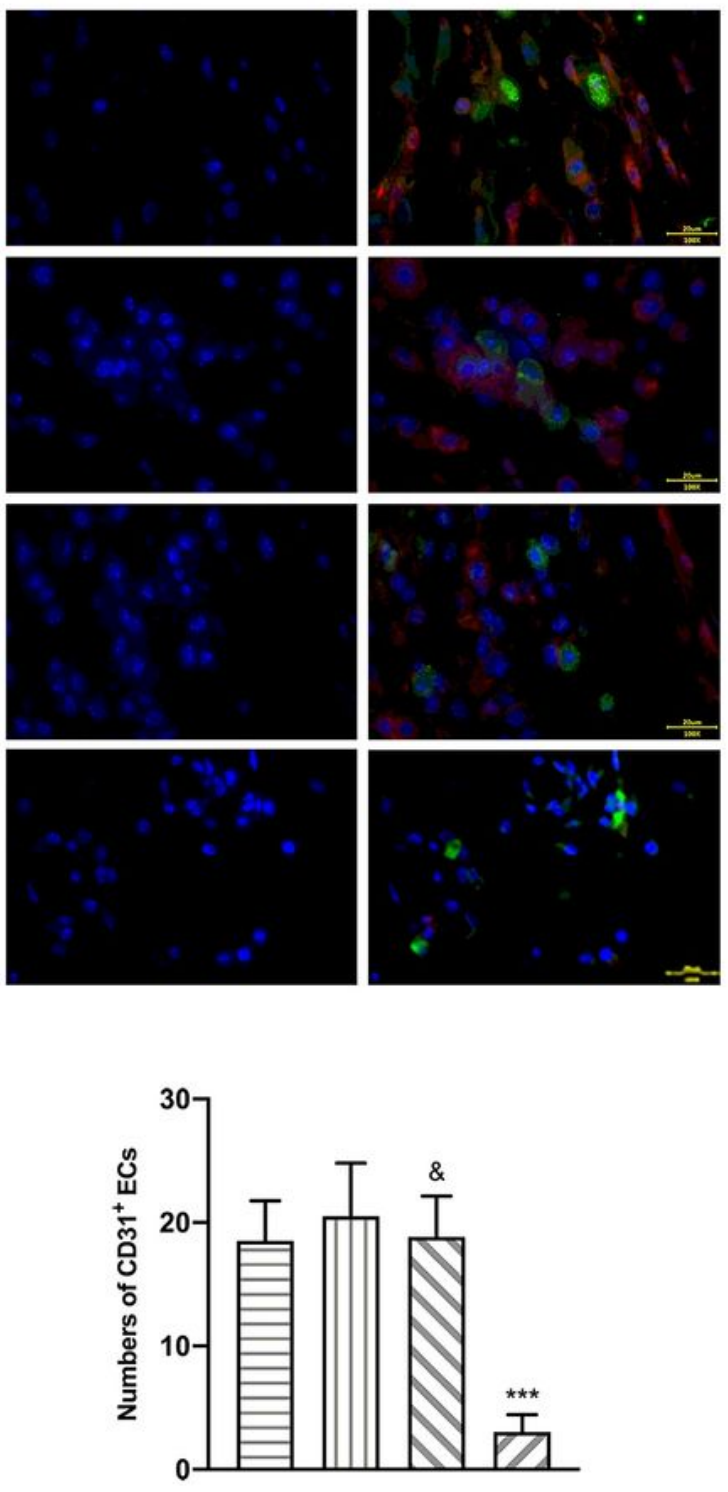

\section{Figure 4}

FZJD improves the therapeutic effect of 5-FU by inhibiting TEMs-mediated angiogenesis. To investigate the effect of FZJD on the pro-angiogenic activity of TEMs in vivo, MFC-bearing mouse model was established. (a) The mice were sacrificed and the tumors were collected, weighed, and imaged. (b) Quantification of the average tumor weight. $\triangle P<0.05$, FZJD+5-FU group vs. FZJD group and 5-FU group; $\star \star \star P<0.00015-F U$ group vs. control group; $* * P<0.01$, FZJD group vs. control group. (c) The tumor 
sections were immunostained with anti-TIE2 or anti-CD31 antibodies to evaluate the role of TEMs in the anti-tumor effect of FZJD. The population of TEMs and CD31+ ECs was quantified from six high-powered fields for each tumor section. Scale bar, $20 \mu \mathrm{m}$. (d) Quantification of the population of TEMs and ECs. \&P $>0.05$, FZJD+5-FU group vs. FZJD, 5-FU, and control groups and 5-FU group vs. FZJD and control groups; $\star \star \star \mathrm{P}<0.0001, \mathrm{FZJD}+5-\mathrm{FU}$ group vs. FZJD, 5-FU, and control groups. 